Historic, Archive Document

Do not assume content reflects current scientific knowledge, policies, or practices. 



\section{The Roosevelt Strawberry}
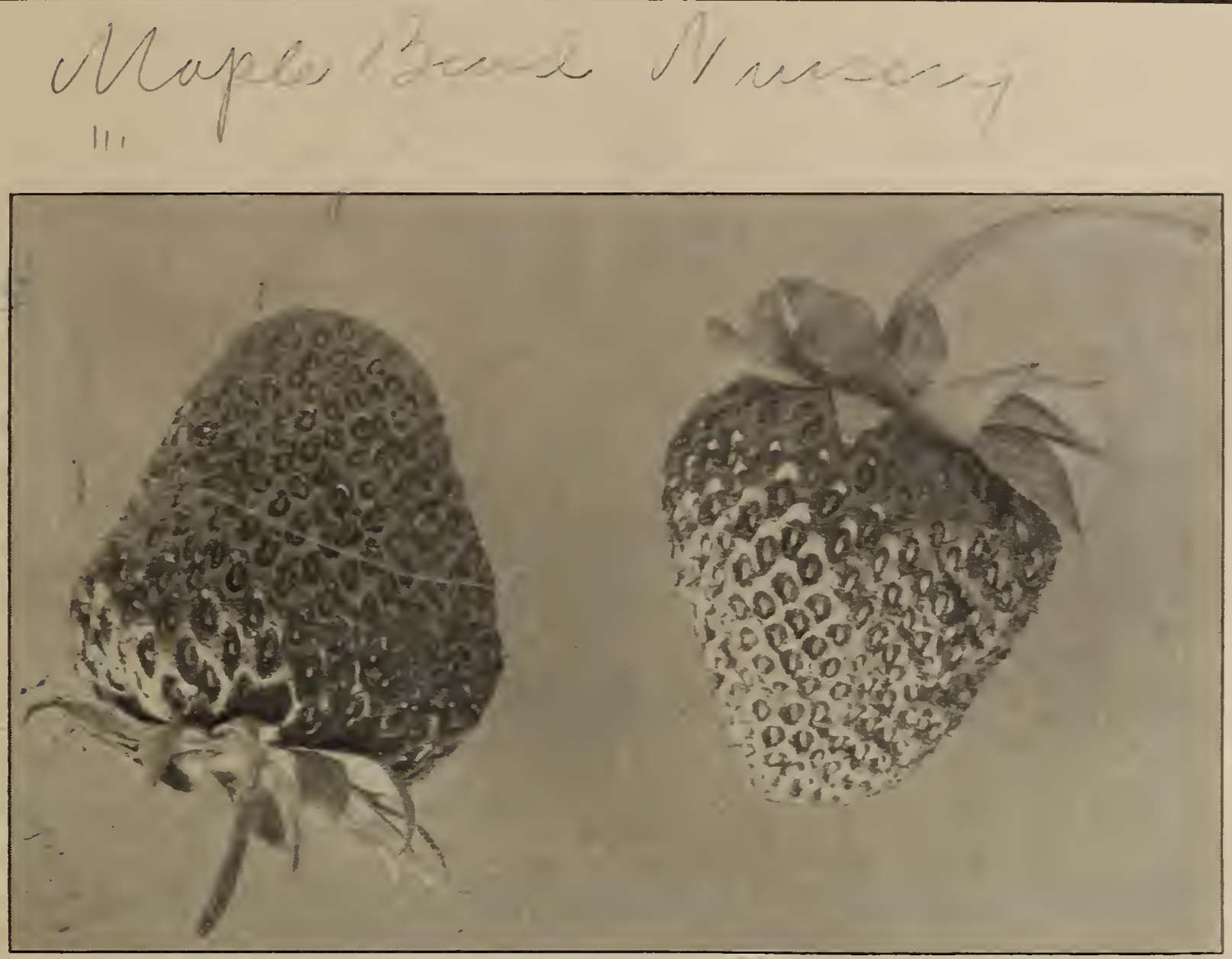

THIS cut gives you the natural size of the ROOSEVELT. 'Tis exact size of the two berries photographed, and an average of the best developed berries grown in a three acre patch, on gravelly soil and without any special care or forcing in any away, and in the very dry season of 1909.

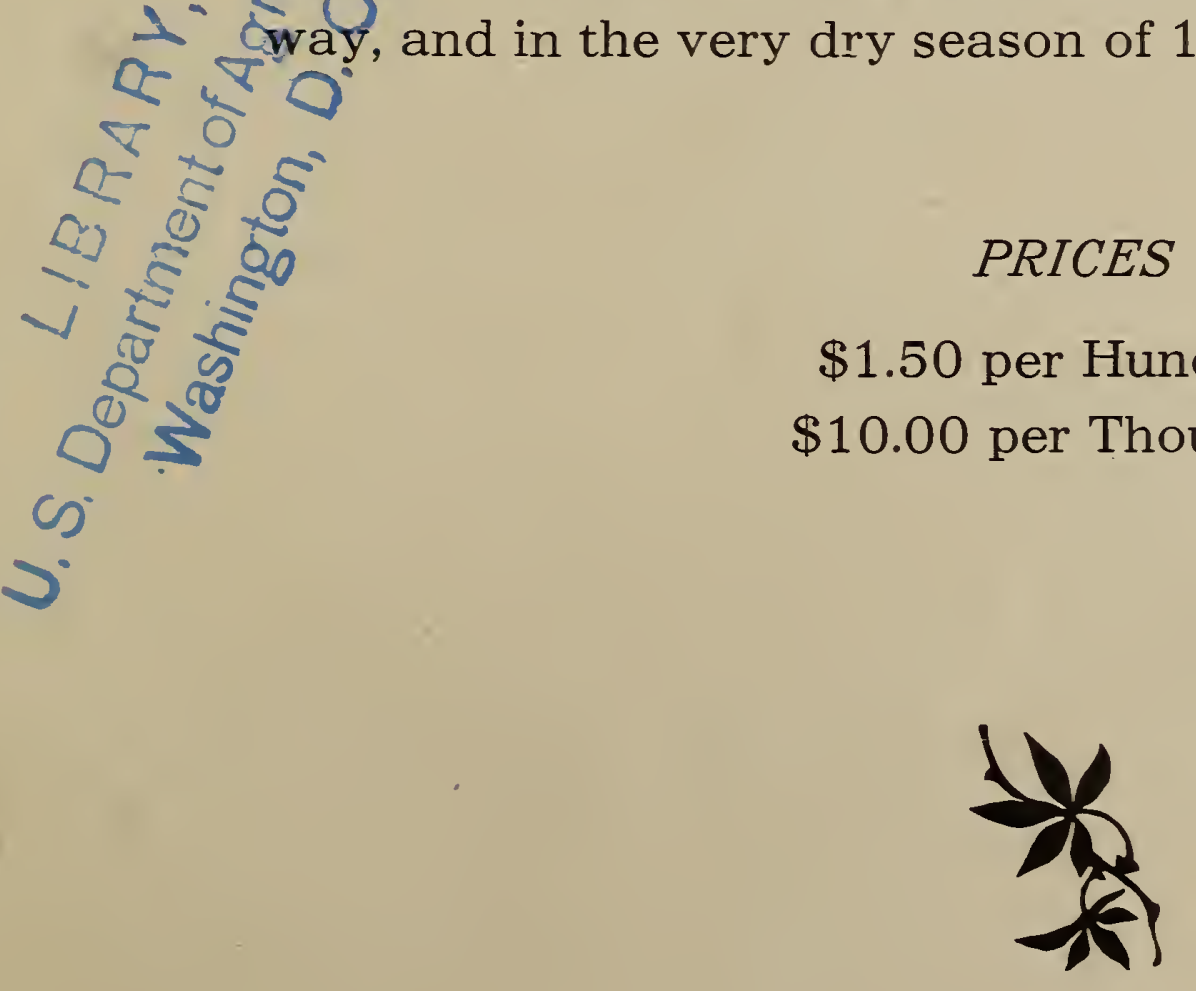




\section{The Roosevelt Strawberry}

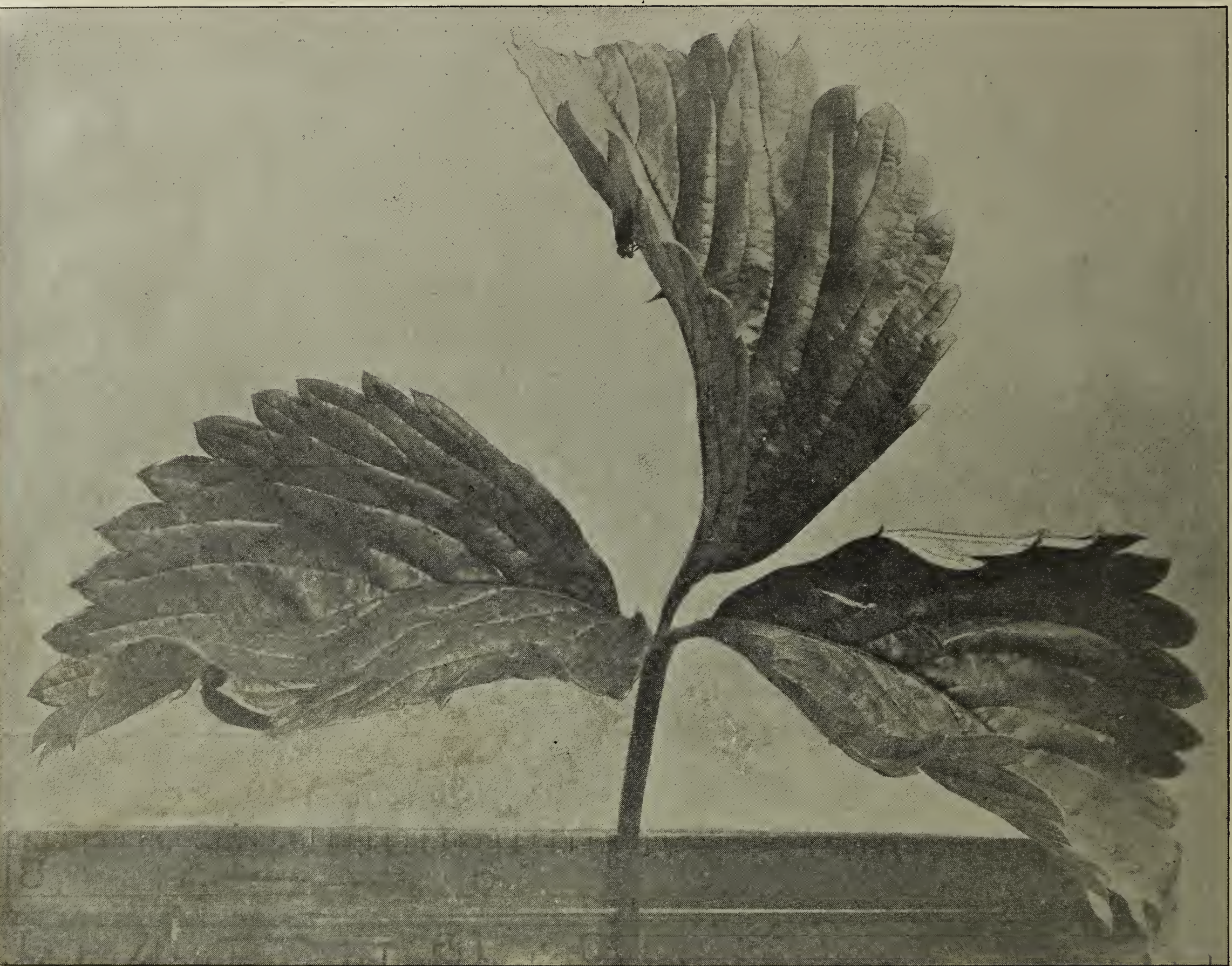

$\mathrm{H}^{\mathrm{ERE}}$ you see the vigorous growth of the plant. Notice the size, eight inches from tip to tip. (No strawberry race suicide here.) The foliage is lusty, the root large and long. The fruit abundant, beautifully shaped, a dark rich red inside and out; flavor unsurpassed, if equaled. Firm and solid, and like the namesake, will stand lots of rough handling and still be a perfect specimen of its kind.

T. B. WEST, PERRY, OHIO, U. S. A. 


\section{The Roosevelt Strawberry}

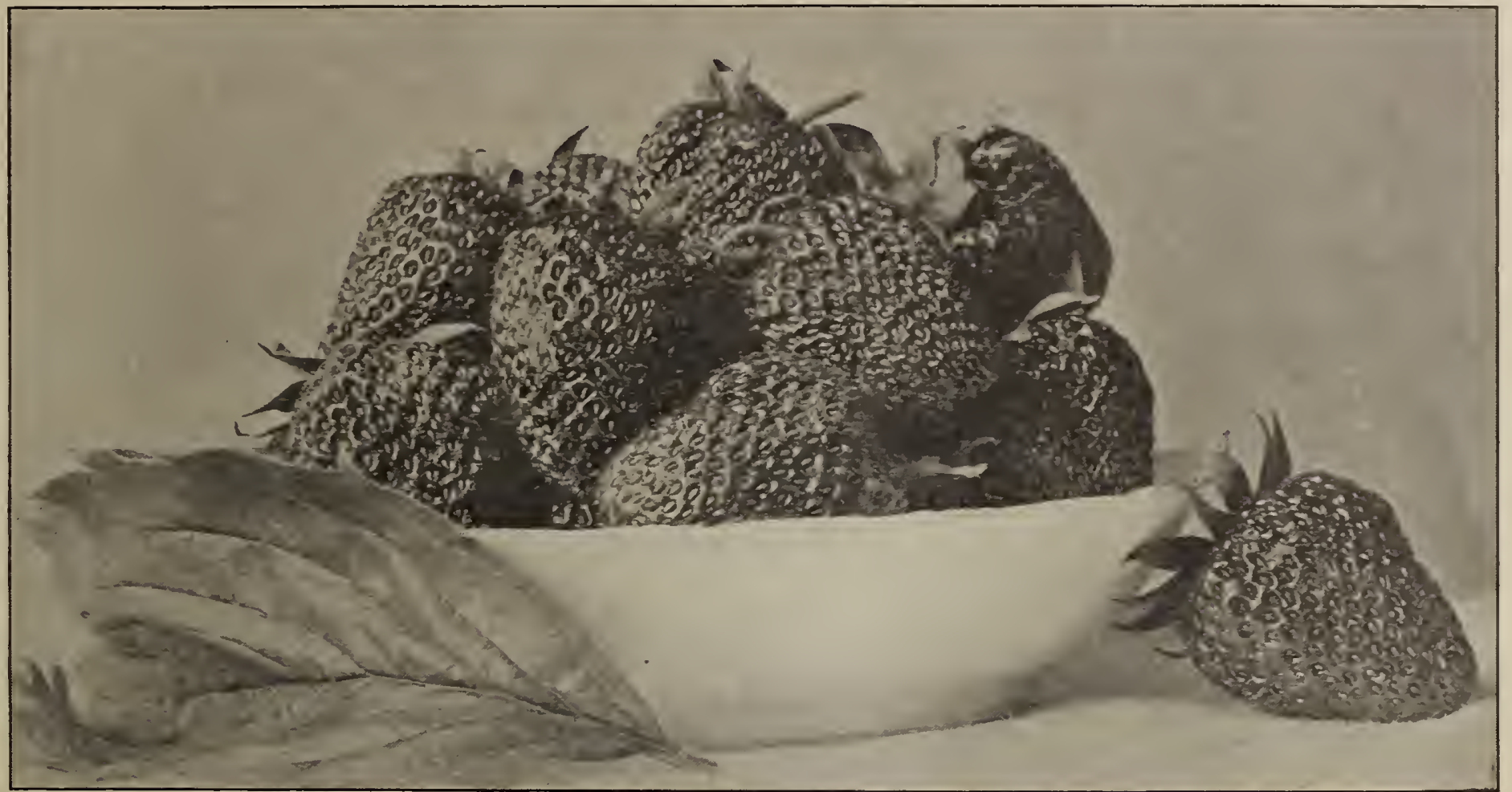

And why the name ROOSEVELT? Because, he who made that name worthy is admitted by all, friend or foe, to be honest, vigorous and true. And that is what I claim for the ROOSEVELT STRAWBERRY.

'Tis honest in its every part, Vigorous in its growth and yield, and True in its form, color, taste, and canning qualities. Hence the name, ROOSEVELT!

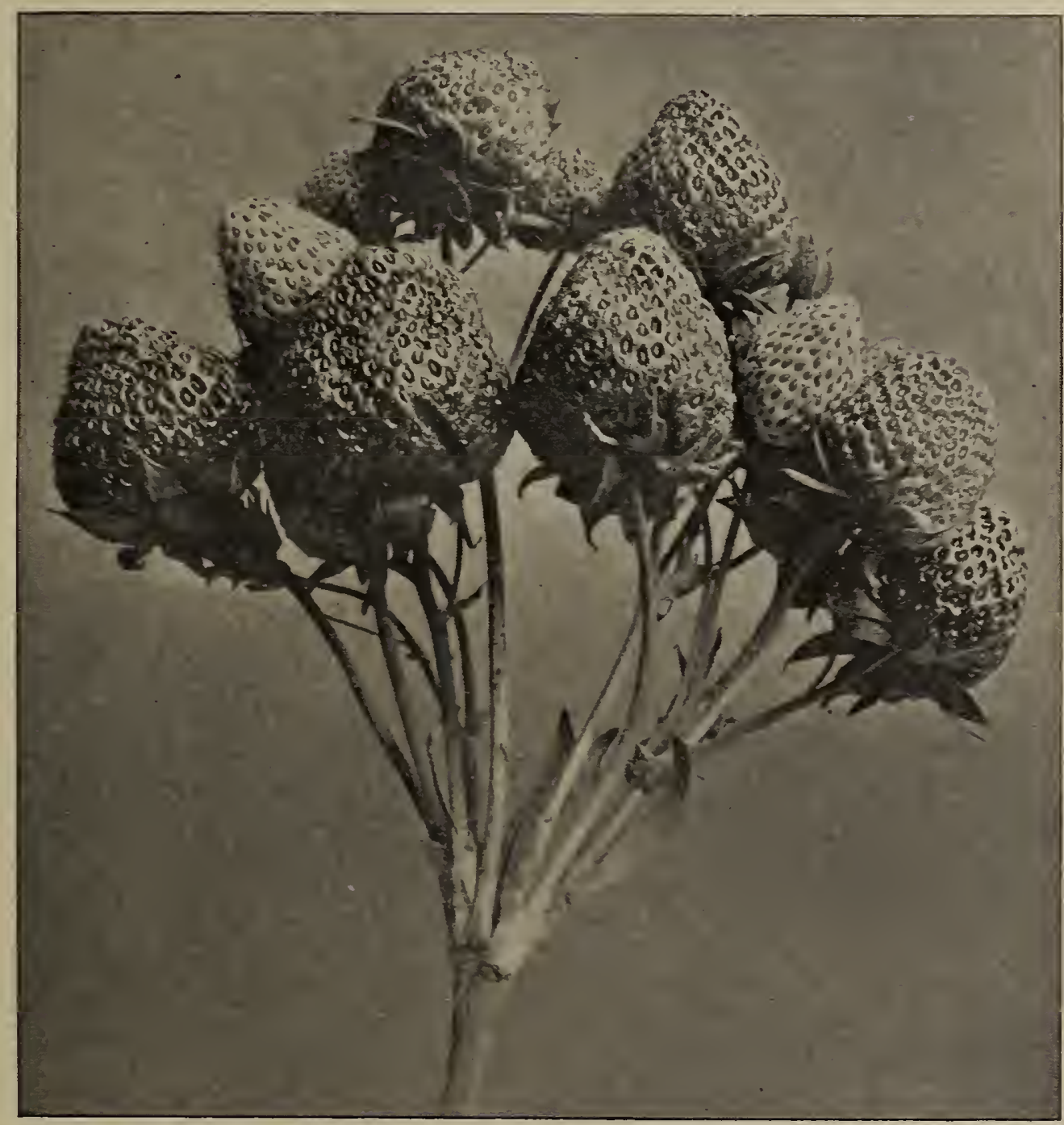

This cut shows the natural growth of the

\section{Roosevelt Strawberry}

'Tis an average cluster on which there are twenty-two perfect strawberries in the various deof development, by noting which you will understand my statement, that the picking season extends from two to three weeks. (See next cut.)

\section{T. B. WEST}

Maple Bend Nursery PERRY, OHIO 


\section{The Roosevelt Strawberry}

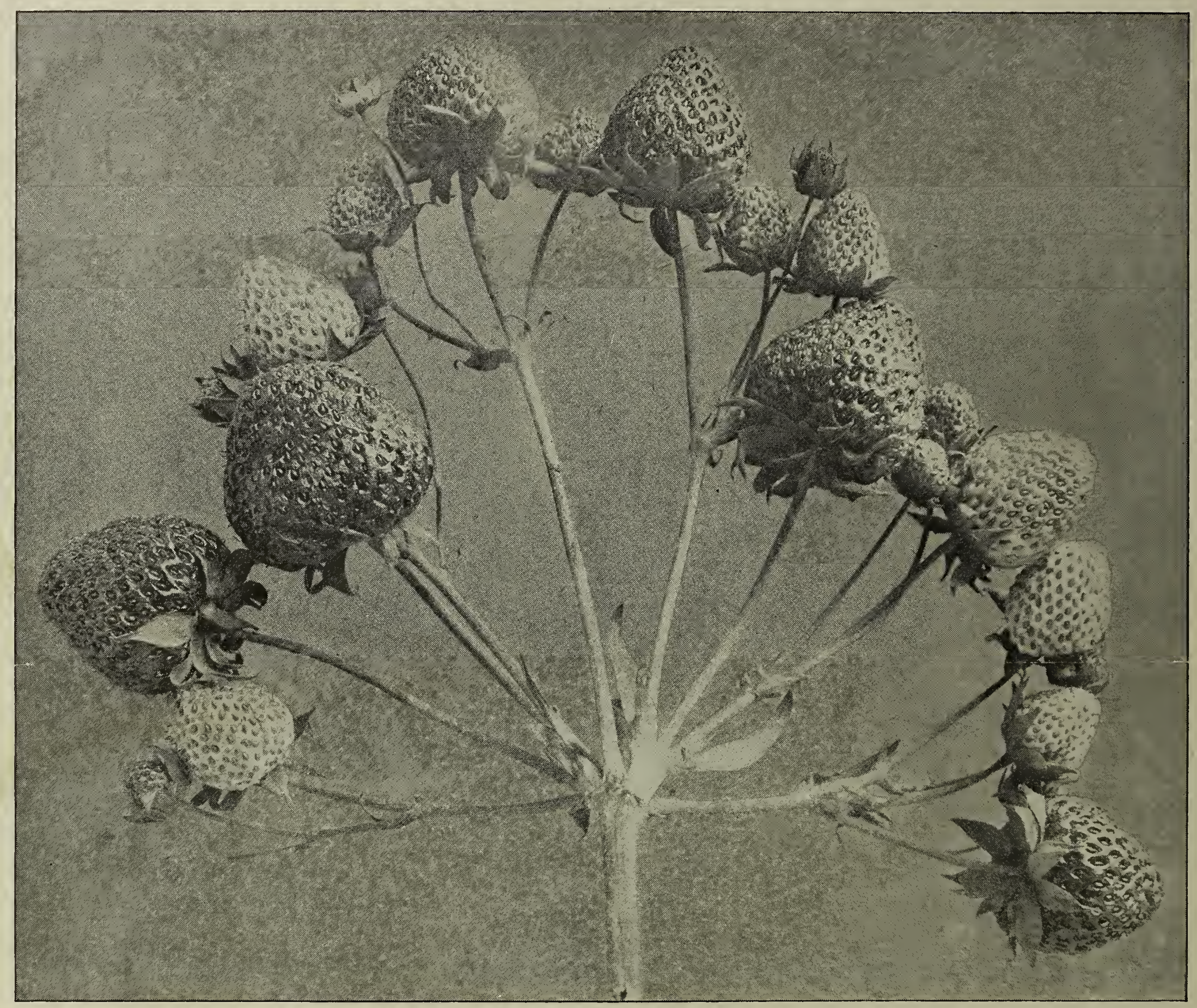

HERE you have the same bunch as shown in the preceding cut. You can count the berries yourself and you will find twenty-two perfect ones.

Note the sturdy growth. The stem is from six to eight inches long and very strong, so as to support the fruit from the ground. If you will visit our fields in the fruiting season, you can see for yourself. 